\title{
Fronteiras culturais no filme El hombre de al lado
}

\section{Pâmela Caroline Stocker}

Doutoranda; Universidade Federal do Rio Grande do Sul

pamelastocker@gmail.com

\section{Resumo}

A partir da observação de pesquisas sobre as fronteiras culturais, este artigo analisa a construção e representação destas fronteiras no filme argentino El hombre de al lado (2009). O objetivo é analisar e refletir sobre as duas sequências que retratam situações de fronteira entre os personagens principais: o primeiro encontro entre eles e a festa na qual um deles aparece sem ser convidado. As ações, interações e representações serão observadas a partir de uma dupla relação: dos personagens entre si e com o contexto social e espacial.

\section{Palavras-chave}

Fronteiras culturais. Cinema. Comunicação.

\section{Introdução}

Margem, limite, borda, linha imaginária. Ainda que a fronteira seja comumente associada à questão de território, podemos caracterizá-la como um espaço de transição no qual se mesclam e convivem diferentes interesses. Mais do que isso, quando relacionamos fronteira à esfera da cultura, somos remetidos às vivências e socialidades, "[...] aos ethos, valores, significados contidos nas coisas, palavras, gestos, ritos, comportamentos e ideias.". (PESAVENTO, 2002, p. 36).

Com um limite sem limites, o caráter móvel e transcendente das fronteiras faz com que Pesavento direcione sua compreensão do fenômeno para além, como uma zona de articulação e intercâmbio entre os homens e o meio em que vivem:

[...] as fronteiras, antes de serem marcos físicos ou naturais, são sobretudo simbólicas. São marcos, sim, mas sobretudo de referência mental que guiam a percepção da realidade. [...], são produtos desta capacidade mágica de representar o mundo por um mundo paralelo de sinais por meio do qual os homens percebem e qualificam a si próprios, ao corpo social, ao espaço e ao próprio tempo. (PESAVENTO, 2002, p. 35). 
Conceito impregnado de mobilidade, nessa conformação a fronteira deve ser considerada não por aquilo que delimita, mas sim por aquilo que é capaz de revelar. Para a autora, torna-se necessário ultrapassar as dimensões política e territorial que estão implícitas e buscar compreender as "percepções" e as "representações", tornando a fronteira conceito possibilitador para se encontrar novos sujeitos, novas construções, novas percepções de mundo.

Identidade que se define por meio da diferença, “[...] a fronteira é um marco que limita e separa e que aponta sentidos socializados de reconhecimento". (PESAVENTO, 2002, p. 36). 0 conceito de alteridade torna-se assim fundamental para compreender a fronteira, pois, segundo a autora, é a partir da delimitação do "quem sou eu" e do "quem é o outro" que a relação pode ser estabelecida. Conforme ressalta ela, na fronteira, ao mesmo tempo em que está muito próximo, o outro é também bem diferente daquilo que somos, pois fala outra língua e tem outros costumes.

Desta forma, segundo Pesavento (2002), a fronteira cultural passa a ser compreendida como trânsito e passagem, sendo capaz de ultrapassar os próprios limites que fixa. Ela proporciona o surgimento de algo novo e diferente a partir do contato, da mistura, da troca, do hibridismo, da mestiçagem cultural e étnica. Isso abre possibilidades de explorar e perceber as trocas culturais em sua ambivalência e ambiguidade para além dos limites e delimitações rigorosas que algumas ciências ou campos do conhecimento exigem.

Nesse contexto, a comunicação é compreendida como processo subjetivo de produção e disputa de sentidos, trama invisível que atravessa os sistemas sociais, presente em todas as interações entre os sujeitos:

[...] prática e construção social por excelência que os seres humanos $(\mathrm{e}$ talvez alguns animais inteligentes) cultivam de forma permanente a fim de expressar a si mesmos - e para si mesmos - em relação ao seu desenvolvimento físico, social e simbólico. (VIZER; CARVALHO, 2009, p. 151, tradução nossa).

Por meio do cultivo reflexivo das relações do mundo da vida, os sujeitos atribuem significação às suas relações e seus contextos. Em outras palavras, essa ciência do sentido atua sobre os próprios processos de formação de sentido na vida social (VIZER; CARVALHO, 2009).

Compreendendo a fronteira para além dos marcos físicos, podemos dizer que ela se constitui a partir de uma construção simbólica de pertencimento. Em outras palavras, no caso das fronteiras culturais, temática deste artigo, é possível afirmar que correspondem a 
um marco de referência imaginária que se define pela diferença. Esse processo pode ser observado em diversas situações retratadas no filme argentino El hombre de al lado. As fronteiras culturais entre os personagens principais da história são constantemente demarcadas e construídas na alteridade, como veremos a seguir.

A película de 2009, dirigida por Mariano Cohn e Gastón Duprat, conta a história de Leonardo (Rafael Spreguelburd), designer industrial que vive com a esposa Ana (Eugenia Alonso), com a filha Lola (Inés Budassi) e com a empregada Elba (Loren Acuña) na única casa construída na América pelo famoso arquiteto Le Corbusier, localizada na cidade de La Plata. A família levava uma vida tranquila até o início das obras em uma casa adjacente, onde o vizinho Victor (Daniel Aráoz) resolveu fazer ilegalmente uma janela cuja vista dá diretamente para a casa de Leonardo.

Já na primeira cena, nos créditos iniciais, vemos a tela dividida ao meio, num rigoroso preto e branco: à direita, uma parede sendo martelada; à esquerda, a mesma parede vista do outro lado. Com o início da abertura da janela, ponto de partida da história, dois seres antagônicos passam a interagir em um mesmo espaço. Isso coloca os telespectadores numa posição privilegiada na observação das relações sociais e interações entre os vizinhos.

Ao longo do filme, as fronteiras culturais entre Leonardo e Victor materializam-se de diversas formas. Nestas cenas, dotadas de valores simbólicos e pontilhadas de manifestações identitárias, é possível perceber a alteridade que delimita e direciona a produção de sentidos sobre os personagens e sobre a trama. Neste artigo, serão pontuadas especificamente duas sequências do filme no qual as relações entre os personagens e o contexto social e espacial em que interagem permitem identificar e refletir sobre as fronteiras culturais traçadas entre eles.

A análise se concentra em duas sequências selecionadas a partir do recorte de situações emblemáticas em que as fronteiras culturais foram observadas: o primeiro encontro entre os vizinhos e a festa na casa de Leonardo. As cenas serão primeiramente descritas procurando contemplar alguns elementos da análise fílmica (plano, enquadramento, som) seguidas da identificação da situação de fronteira cultural e interpretação a partir da observação de pesquisas sobre as fronteiras. 


\section{Espaço fílmico e a construção das fronteiras culturais}

Em entrevista exclusiva ao La Latina ${ }^{1}$ (site brasileiro especializado em cinema latino), o diretor Gastón Duprat afirmou que El hombre de al lado é um filme sobre o medo do desconhecido, daquilo que é diferente. Por tratar de um tema que afeta a todos nós em diferentes níveis, o cineasta classifica a película como universal. Sua percepção e o desenvolvimento do roteiro estão em consonância com o que diz Wittgenstein (apud GEERTZ, 1989, p. 23) quando afirma que um ser humano pode ser um enigma completo para outro ser humano. 0 autor relembra nossa total incapacidade de nos situar em meio ao diferente ou de uma cultura que não seja a nossa: ainda que dominemos o idioma falado em um país desconhecido, por exemplo, não somos capazes de nos situar completamente nele.

Sob o prisma da cultura, compreendida como um contexto dentro do qual é possível descrever, de forma inteligível, os acontecimentos sociais, os comportamentos, instituições ou processos, a relação entre os personagens Leonardo e seu vizinho Victor pode ser caracterizada a partir do "choque" cultural observado em diversas situações ao longo da película.

Com base no conceito essencialmente semiótico de cultura de Geertz, que acredita, como Max Weber, que o homem é um animal amarrado às teias de significados que ele mesmo teceu, assume-se a cultura como sendo essas teias e a sua análise (GEERTZ, 1989). As situações de fronteira presentes no filme El hombre de al lado permitem expor as normalidades de cada um dos vizinhos sem reduzir suas particularidades (GEERTZ, 1989), além de identificar um sistema de símbolos que define os diferentes lugares que cada um ocupa nos espaços sociais.

Analisar um filme, de acordo com Penafria (2009), é sinônimo de decompor esse mesmo filme. Embora não exista uma metodologia universalmente aceita para se proceder à análise fílmica (AUMONT, 1999), a autora sustenta que analisar implica duas etapas importantes: em primeiro lugar decompor, ou seja, descrever; em seguida, estabelecer e compreender as relações entre esses elementos decompostos, ou seja, interpretar (VANOYE; GOLLIOT-LÉTÉ, 1994). Segundo o Dicionário teórico e crítico de cinema, de Jacques Aumont e Michel Marie (2006), é ainda "[...] indispensável levar em conta a narrativa, sendo o espaço, entre outros, definido pelos acontecimentos que nele tomam lugar". (AUMONT; MARIE, 2006, p. 104). 
Nessa direção, o objetivo da análise fílmica seria explicar/esclarecer o funcionamento de um determinado filme e propor-lhe uma interpretação. Porém, a autora atenta para um texto de Susan Sontag, datado de 1961, que afirma que o cinema não deve ser interpretado apenas em seu conteúdo (história contada, diálogos), mas deve levar em conta os seus aspectos formais. "A sua proposta vai no sentido da análise, que permite ver mais e ouvir mais - enquanto experiência dos sentidos - em vez de escavar significados ocultos". (PENAFRIA, 2009, p. 3). Para a autora, é isso que difere a análise fílmica da crítica de cinema.

Penafria (2009) observa ainda que a análise de filmes deverá ser realizada tendo em conta objetivos estabelecidos a priori, visto que se trata de uma atividade que exige observação rigorosa, atenta e detalhada a, pelo menos, alguns planos de um determinado filme. Dito isso, a análise a seguir procura observar as ações, interações e representações a partir da relação dos personagens centrais e seu contexto social e espacial em duas sequências do filme.

\subsection{A primeira mirada: encontro entre vizinhos}

0 primeiro encontro entre Leonardo e o vizinho Victor acontece no dia seguinte ao início das marretadas e a derrubada de parte da parede. Leonardo está em seu escritório, falando ao telefone com um cliente alemão, quando ouve mais uma vez o barulho da obra.

Visivelmente irritado, vai até a janela e chama por alguém. Quem lhe atende é Victor. Suas primeiras palavras com o vizinho tratam de dissuadi-lo de continuar abrindo a janela, argumentando que tal ato seria ilegal. Sua intenção é fazê-lo parar imediatamente. Em contrapartida, quando toma a palavra, apesar do tom sério, Victor mostra-se educado, explica seu ponto de vista sem rodeios e justifica: precisa de luz, alguns raios de sol que, em suas palavras, não farão falta a Leonardo. Em seguida, pede que o vizinho venha até sua casa para conversarem sobre o assunto.

Leonardo nega o pedido do vizinho, esgueira-se dizendo que está ocupado e retoma sua argumentação: repete que a janela de frente para a sua casa é ilegal e reclama que o vizinho estaria invadindo a sua privacidade e a de sua família. Leonardo se mostra cada vez mais irritado, diz que não tem tempo para conversar; quer apenas que o buraco da parede seja fechado. Após uma longa mirada silenciosa, Victor assente: vai pedir aos homens para que o buraco seja coberto com uma lona. 
Figura 1 - Cena do primeiro contato entre Leonardo e o vizinho Victor pelo buraco aberto na parede

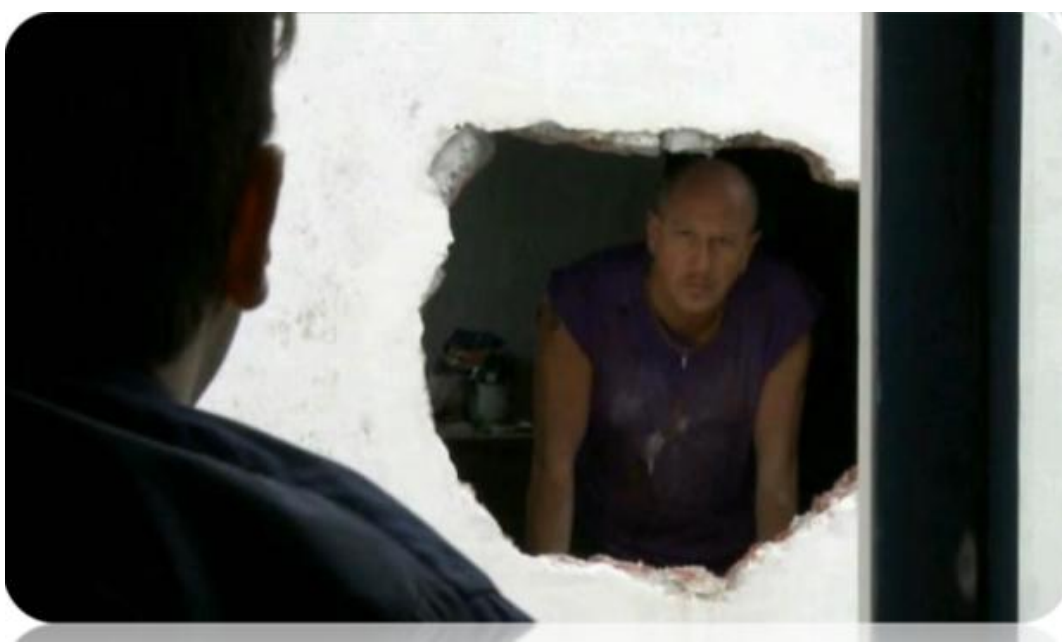

Fonte: $O$ Homem ao lado (2009).

A situação extraordinária (AGIER, 2011) e imprevista entre os vizinhos ilustra o fenômeno fluido e incerto que se determina fundamentalmente por sua localização fixa, a relação entre os indivíduos e a sociabilidade é observável e significante, enquanto que as trocas entre os indivíduos, o espaço e a sociabilidade são imprevistas e problemáticas.

Constroem-se assim, aos olhos do público, dois personagens antagônicos. De um lado, e fazendo papel de bom moço, adequado às convenções e expectativas, está Leonardo, um designer conceituado, poliglota e premiado. Do outro, rústico, direto e invasivo, Victor, com seu vocabulário grosseiro, despreocupado com a aparência ou com a sua postura.

Na Figura 1 é possível observar o enquadramento de cena que é dado a todo o diálogo entre os personagens. Nada mais gráfico e simbólico do que a escolha do plano fixo que privilegia o ponto de vista de Leonardo. Só visualizamos o vizinho de frente sempre pelo mesmo ângulo e enquadramento e vemos Leonardo de costas ou de perfil, em primeiro plano, mas sem mostrar-se por inteiro. Essa estratégia é utilizada ao longo de toda a película em grande parte das cenas de encontro entre Leonardo e Victor (figuras 2, 3 e 4). Isso ocorre porque a trama é narrada do ponto de vista de Leonardo. Para o filme, é como se nós, os espectadores, fossemos representados por Leonardo. Victor é o estranho, o diferente, por isso ele é enquadrado, na maioria das vezes, frontalmente; ele é o ser que precisa ser observado e desvendado pelo olhar do espectador. 
Figura 2 - No segundo encontro entre os vizinhos, Victor vai à casa de Leonardo convidá-lo para conversar sobre a reforma

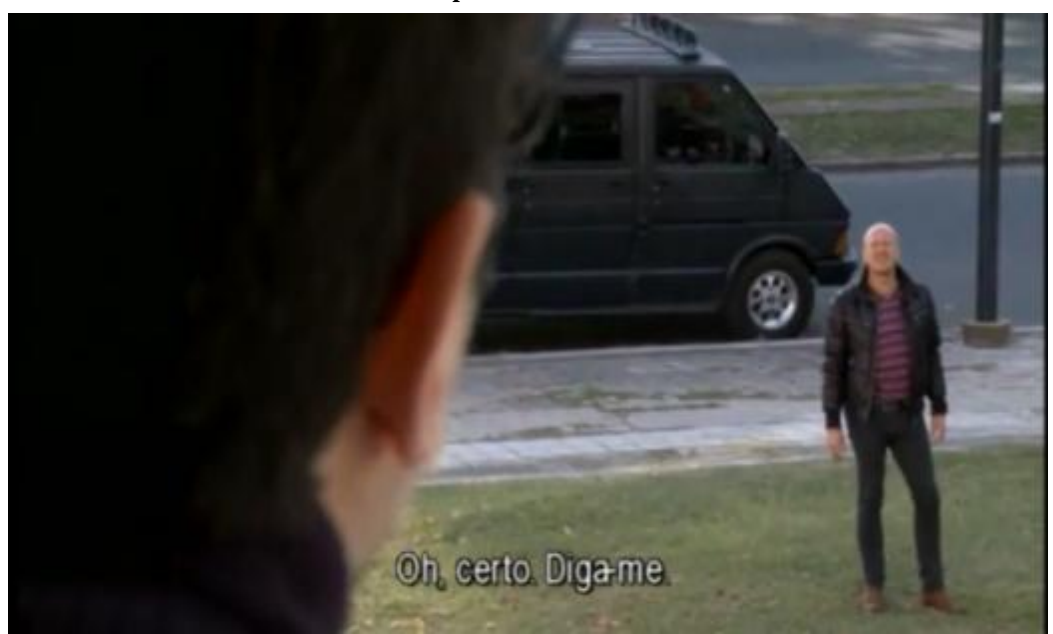

Fonte: O Homem ao lado (2009).

Figura 3 - Em mais uma conversa pela janela, Leonardo chama o vizinho e oferece ajuda financeira para que possa acelerar a obra

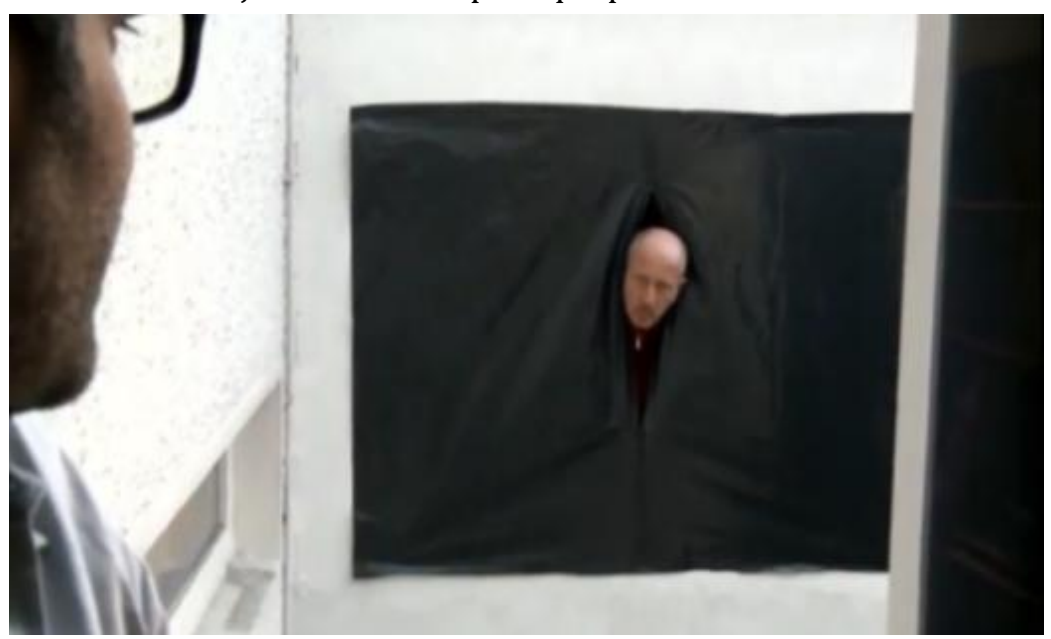

Fonte: O Homem ao lado (2009). 
Figura 4 - Leonardo chama o vizinho a fim de saber porque a janela ainda não fora fechada

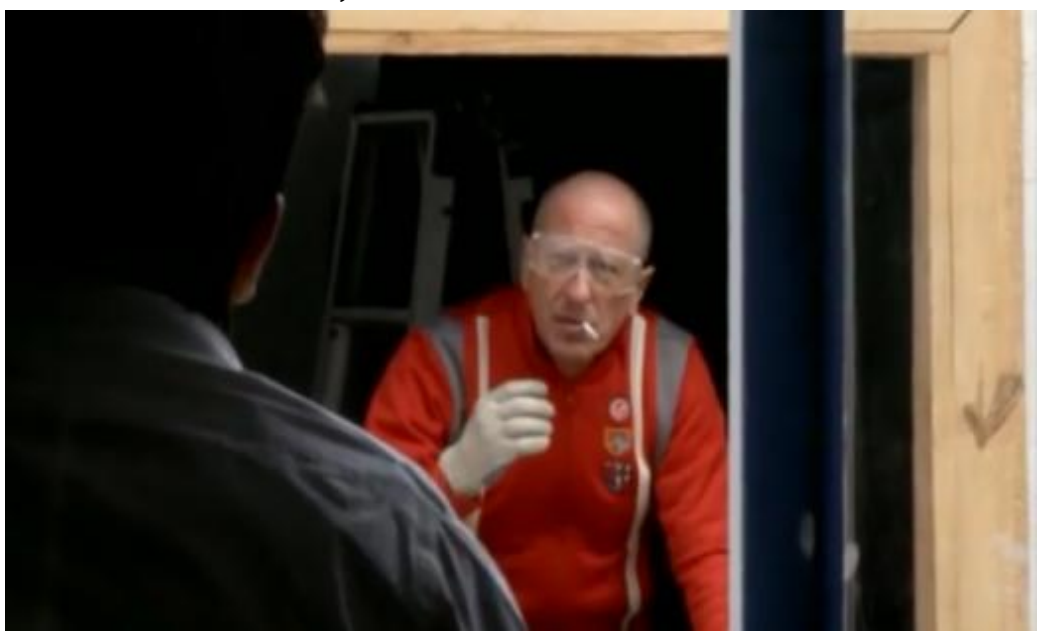

Fonte: O Homem ao lado (2009).

Nas situações retratadas nas figuras 2, 3 e 4, o tom de voz e a seriedade com que Victor se dirige a Leonardo contrastam com a educação e simpatia que procura esboçar quando o encontra. Além de repetir diversas vezes o convite para que ele venha a sua casa, Victor demonstra gentileza em diversos momentos na busca pela amizade do vizinho: envia flores, compartilha uma conserva a base de carne de javali e presenteia Leonardo com uma escultura feita por ele mesmo, com canos de armas de fogo. As três situações são motivo de desconforto para o designer, que parece aceitar os agrados por medo e para não contrariar o vizinho.

Essa insegurança demonstrada por Leonardo e a ideia de que o perigo está em toda a parte é evocada por Bauman (2009) quando se refere ao individualismo moderno, inerente a nossa sociedade. Conforme o autor, suspeitamos dos outros e de suas intenções e nos recusamos a confiar no desconhecido:

[...] quanto mais as pessoas se isolam nessas comunidades muradas feitas de homens e mulheres semelhantes a eles mesmos, menos são capazes de lidar com os estrangeiros; e quanto menos são capazes de lidar com os estrangeiros, mais têm medo deles. Por isso, procuram cada vez mais avidamente a companhia dos seus semelhantes. (BAUMAN, 2009, p. 85).

As diferenças entre os sujeitos elencadas ao longo da história determinam a natureza das fronteiras culturais traçadas durante o filme. De acordo com Bauman (2009, p. 44), há um "[...] impulso em direção a ilhas de identidade e semelhança espalhadas no grande mar 
da variedade e da diferença". Somos conduzidos pelos diretores da película a nos posicionar ao lado de Leonardo, observando a situação retratada do seu ponto de vista e a partir de suas angústias e aflições. 0 vizinho é apresentado como o estrangeiro, o exótico e o diferente, como a alteridade com a qual é preciso lidar e em relação a qual é preciso demarcar diferença.

[...] ao contrário da equivocada opinião comum - as fronteiras não são traçadas com o objetivo de separar diferenças. Ao contrário, justamente porque se demarcam fronteiras é que, de repente, as fronteiras emergem, que as percebemos e nos tornamos conscientes delas. Melhor dizendo, vamos em busca das diferenças justamente para legitimar fronteiras. (BAUMAN, 2009, p. 75).

Essa necessidade de legitimar as fronteiras entre os dois personagens pode ser observada em diversos momentos do filme. Quando Leonardo descreve Victor para seus amigos, em uma cena em que está jantando com os seus iguais, se refere a ele como "[...] um tipo brega, determinado e muito insistente". Descreve seu encontro com Victor como "um exercício antropológico" e o bar onde foram conversar como "repugnante", menosprezando o vocabulário e os modos do vizinho, classificando-o como "troglodita".

\subsection{A mirada do outro}

A presença da janela e do vizinho causam fissuras e abalam, ao longo do filme, a estrutura de Leonardo. Desde o primeiro encontro entre eles, o personagem mostra-se confuso e vacilante. A cena que sucede o primeiro diálogo entre ambos mostra Leonardo solitário e pensativo, num ambiente escuro e em contraluz ao som da chuva que cai do lado de fora. 
Figura 5 - Leonardo após a primeira conversa com Victor, pensativo e solitário, em cena escura e em contraluz

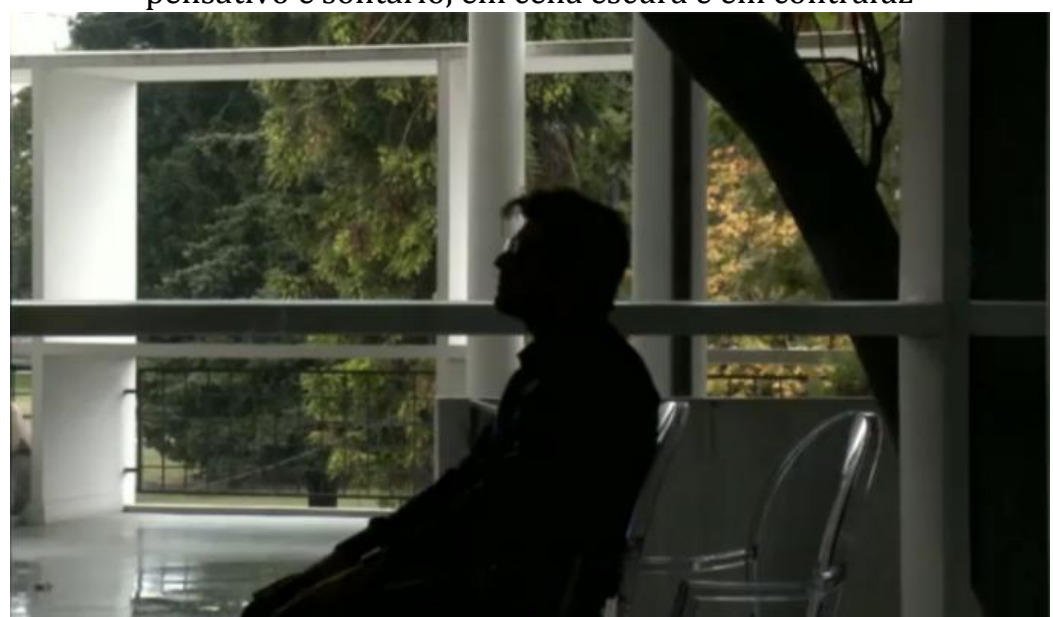

Fonte: O Homem ao lado (2009).

A partir da primeira negociação acerca da janela e do conflito que prossegue ao longo da película, é possível identificar o caráter vacilante do personagem Leonardo: incompleto e desorientado, incapaz de resolver a situação com o vizinho, ele se revela fragmentado. Em contrapartida ao seu sucesso profissional, o matrimônio e a relação com a filha adolescente são problemáticos e expõem o vazio de sua vida afetiva. Em diversas cenas ao longo do filme, quando em interação com a esposa Ana e a filha Lola, essa incompletude fica clara nas imagens em que o designer não se revela por inteiro: com o rosto escondido na cena em que prepara um frango para o jantar e relata à esposa sua primeira conversa com o vizinho (Figura 6); de cabeça para baixo quando retratado pela câmera do sogro (Figura 7); escondido e fragmentado mais uma vez na presença da esposa Ana enquanto fala ao telefone (Figura 8) e nos espelhos do quarto da filha, quando tenta dialogar com ela (Figura 9). Nunca o vemos completo ou de frente, exceto quando está com alunos ou amigos de sua mesma classe social ou de relações de trabalho. 
Figura 6 - Após o primeiro contato com o vizinho, Leonardo tem o rosto oculto pelo móvel da cozinha enquanto prepara o jantar e conta o ocorrido à esposa

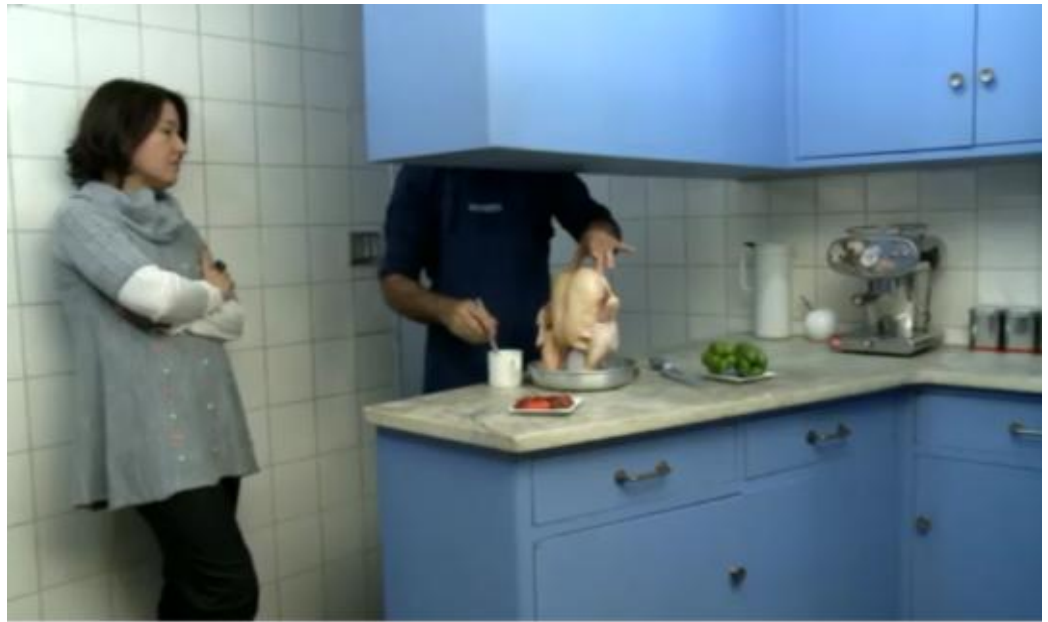

Fonte: O Homem ao lado (2009).

Figura 7 - Retratado pelo sogro, que testava a câmera de vídeo recém-comprada, Leonardo aparece de ponta-cabeça

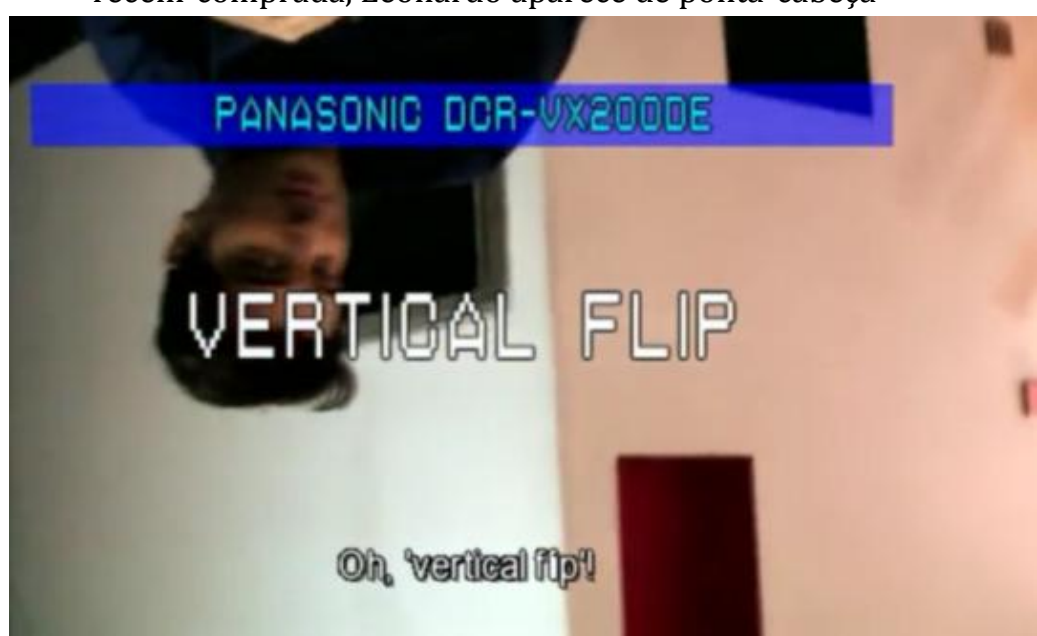

Fonte: O Homem ao lado (2009). 
Figura 8 - Leonardo e a esposa Ana, ambos parcialmente revelados por entre os objetos

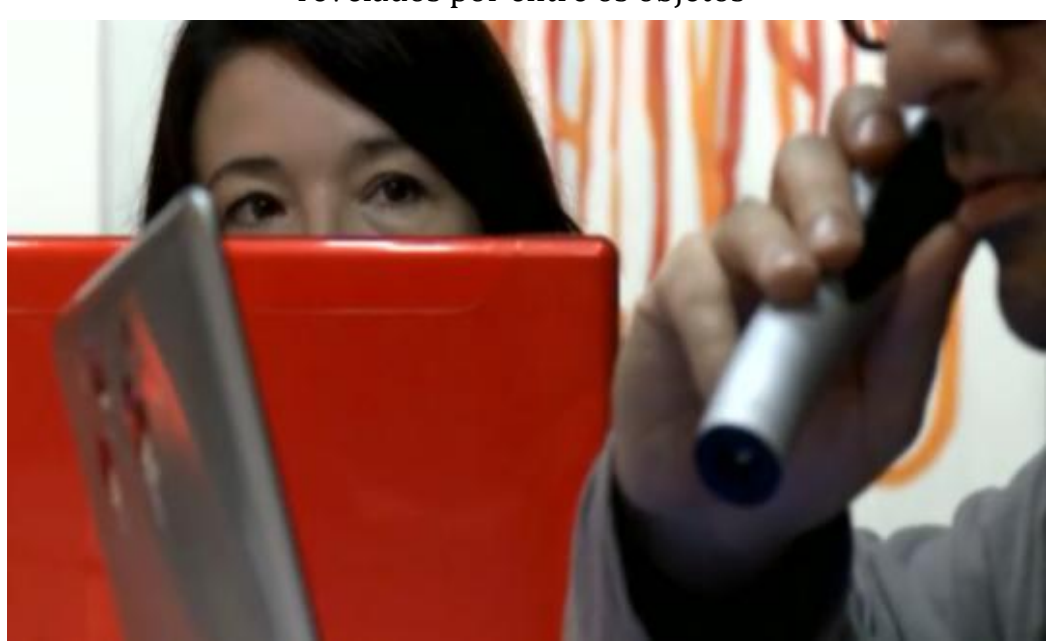

Fonte: O Homem ao lado (2009).

Figura 9 - A imagem de Leonardo fragmentada novamente, desta vez nos espelhos do quarto da filha Lola, numa das tentativas de diálogo com ela

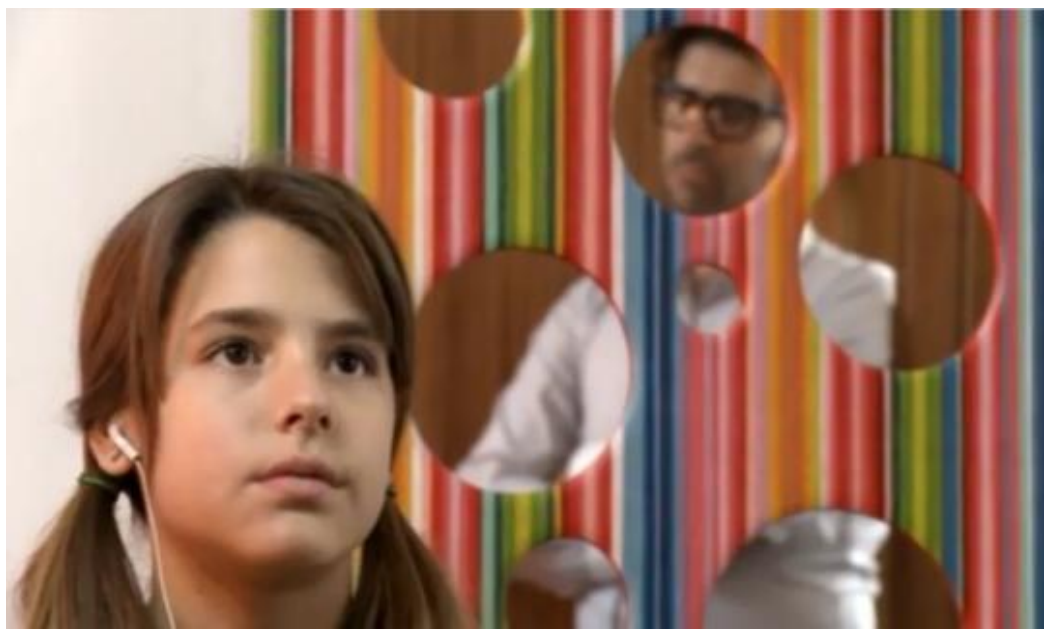

Fonte: O Homem ao lado (2009).

A máxima frustração e fragilidade do protagonista ocorre após infindáveis idas e vindas na negociação sobre a abertura da janela. Quando finalmente chega a um acordo com o vizinho, que concorda em fazer uma abertura mais fina e com vidros foscos, sua esposa mostra-se irredutível: não aceita nenhum tipo de abertura e exige que tudo volte a ser como antes. Frente ao novo impasse, arrasado, ele dirige seu carro em meio à neblina e põe-se a chorar, totalmente impotente frente à situação. 


\subsection{Festa na casa de Leonardo: convidado indesejado}

As situações rituais (AGIER, 2011) são marcadas por uma distância do cotidiano regrado. Num espaço delimitado e apropriado, o tempo de um acontecimento ritual, um encontro, é simbolizado entre indivíduos e um coletivo, visível ou não. No caso do filme em questão, a festa promovida por Leonardo e a esposa em sua casa torna-se um lugar privilegiado de elaboração e aplicação de estratégias identitárias coletivas, mesmo que a cidade ao redor proponha outras formas de classificação social.

Na cena a seguir, a da festa promovida por Leonardo em sua casa, é possível observar essa situação. Durante todo o filme, percebemos a desconfiança e o esforço da família para não dar abertura ou criar laços amigáveis com Victor. Vemos, também, em uma das cenas, a hesitação de Leonardo até mesmo em passar o número de seu telefone ao vizinho. Porém, Leonardo e a esposa se veem obrigados a compactuar com a presença nada discreta de Victor em sua festa. Ele aparece como acompanhante de uma das alunas de yoga de Ana, que foram convidadas a trazer seus namorados. Apesar do desconforto aparente dos anfitriões, Victor e a namorada não se inibem, dançam e mostram-se completamente à vontade na festa.

Figura 10 - A festa promovida por Leonardo e sua esposa recebe um convidado inesperado e indesejável: o vizinho

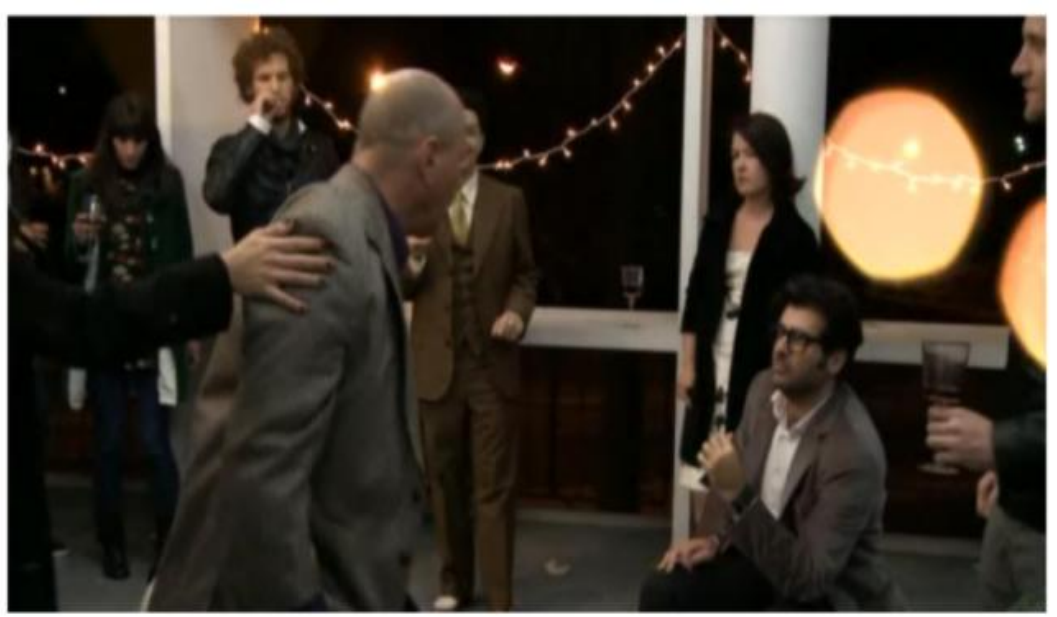

Fonte: $O$ Homem ao lado (2009).

Diversas mentiras e omissões de Leonardo vêm à tona com a presença do vizinho no espaço da casa e na presença de Ana. Uma das primeiras indagações de Victor refere-se à 
escultura com a qual presenteou Leonardo (e este mentiu para a esposa ser presente de um aluno). No segundo momento de interação entre o casal e o vizinho, Victor lamenta o posicionamento do sogro e "proprietário da casa" em relação à janela, revelando mais uma das mentiras ditas por Leonardo na negociação e que não era de conhecimento da esposa.

As relações entre indivíduos, espaço e sociabilidade mostram-se observáveis, significantes e necessárias nessa situação. As cenas finais da sequência, que retratam Victor sorridente balançando-se na cadeira premiada criada por Leonardo, combinam um enquadramento fixo que revela esporadicamente o sorriso de Victor com uma trilha sonora instrumental que evoca o clima tenso provocado pela presença dele na casa. Em cena anterior, quando apresentava a cadeira para o seu advogado, Leonardo explica que a base esférica e a ausência de um ponto de apoio fixo faz com que seja possível balançar-se em direções diferentes. Parte da ideia, segundo o designer, é que a pessoa que está sentada sinta-se flutuando. É exatamente essa sensação transmitida pela parte final da sequência.

Figura 11 - Victor agradece aos anfitriões e diz ser um sonho realizado ter a amizade de Leonardo e da sua esposa e estar em sua casa

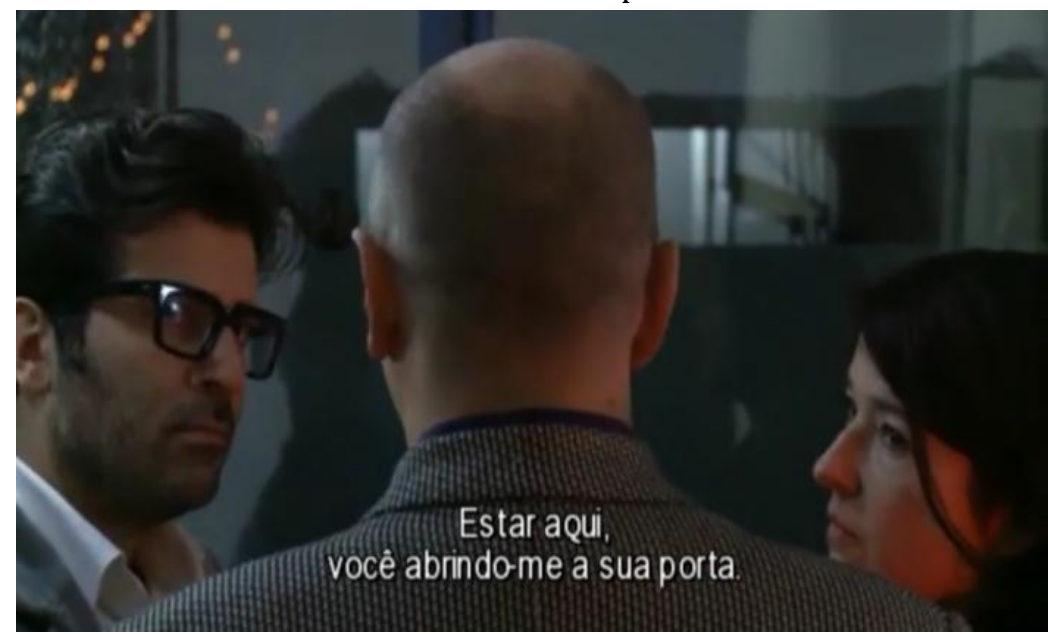

Fonte: O Homem ao lado (2009). 
Figura 12 - Cenas finais da sequência da festa, na qual Victor flutua na cadeira premiada criada pelo designer

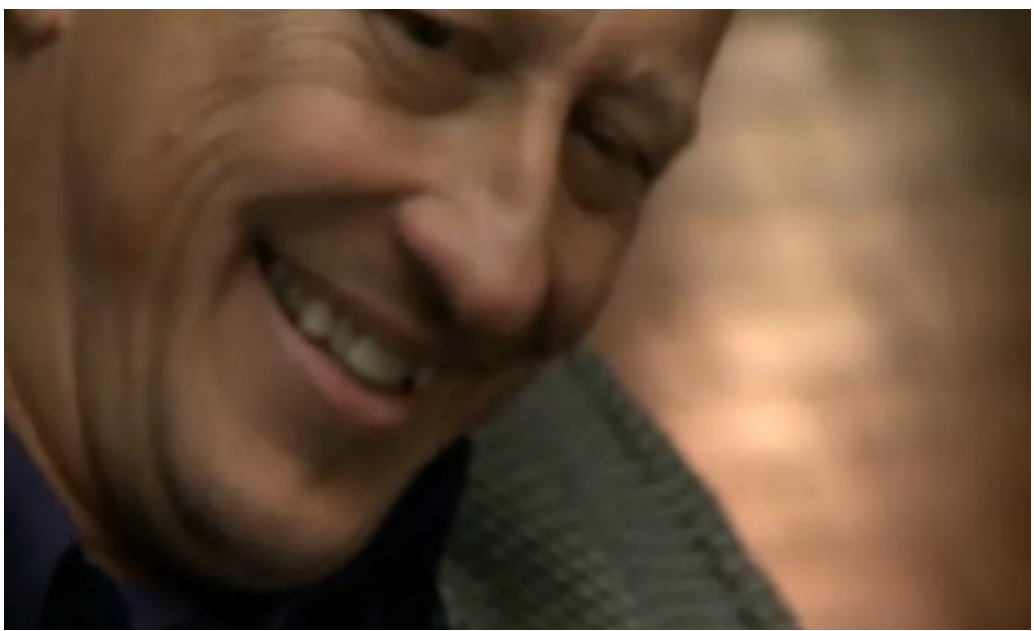

Fonte: O Homem ao lado (2009).

Nesse contexto, Bauman (2009) relembra que algumas fronteiras incomodam e impedem o indivíduo de agir amistosamente ou de sentir interesse pelo outro. Independente de quais sejam essas diferenças, o que as determina é a natureza das fronteiras que traçamos:

As diferenças que se tornam significativas e importantes em decorrência da natureza da fronteira, e as intenções que estão por trás dessa fronteira, são diferenças atribuídas a pessoas que demonstram a indecente tendência a ultrapassar as fronteiras e aparecer de surpresa em locais para os quais não foram convidados [...]. (BAUMAN, 2009, p. 77).

A sequência do filme que retrata a festa na casa de Leonardo é emblemática nesse sentido, por traduzir o sentimento de invasão, desconforto, desconfiança e de convivência forçada pela diferença.

\section{Considerações finais}

Com um argumento aparentemente simples - a abertura de uma janela e o posterior conflito entre vizinhos - o filme El hombre de al lado levou às telas em 2009 uma história atemporal, capaz de provocar um jogo de olhares sobre as relações sociais e a realidade contemporânea. 0 discurso narrativo dos diretores Mariano Cohn e Gastón Duprat enfatiza a relação entre aquilo que permitimos mostrar e ocultar de nós mesmos como sujeitos e atores sociais. 
Pode-se dizer que a janela simboliza a ruptura de barreiras sociais e não apenas arquitetônicas na relação entre Leonardo e Victor. A abertura violava a casa obra-de-arte, por ser esteticamente inconcebível naquele contexto, mas violava também Leonardo e o verniz de sua tão sólida estrutura de profissional de sucesso e pai de família exemplar. Ao ser confrontado cara a cara com o outro, o personagem finalmente coloca em xeque a si mesmo a partir da diferença. A relação conturbada com a esposa, a filha que não lhe dirige a palavra, o fracasso com os alunos, entre outras frustrações, fazem com que o conflito com o vizinho torne-se a gota d'água de sua rotina.

A perspectiva adotada pelos diretores, de posicionar o expectador a enxergar as coisas do mesmo ponto de vista que Leonardo, faz com que em nenhum momento possamos "ver" Victor por inteiro. A percepção que construímos acerca do personagem, apresentado como exótico e estranho, é realizada a partir daquilo que Leonardo permite perceber sobre o vizinho. Descobre-se então o outro com a mesma curiosidade, temor e receio apresentados pelo designer. Da mesma forma, a casa de Victor só é percebida pela narrativa fora de campo, no qual apenas é permitido ouvir alguns sons e espiar aquilo que é possível vislumbrar pelo buraco na parede. Se em sua crise de identidade e fragmentação Leonardo revela-se para o expectador a cada ato, até o final da película esse "outro" segue como um enigma para o público.

Ainda que as fronteiras entre Victor e Leonardo tenham sido constantemente demarcadas ao longo de todo o filme, as sequências escolhidas para a análise permitiram uma compreensão mais clara acerca do papel desempenhado pela alteridade na construção dos personagens e situações de interação entre eles.

As fronteiras culturais, espaços unicamente imaginários, ganham materialidade nas duas sequências analisadas e em tantos outros momentos retratados pelo filme. 0 tom de voz e os modos de dirigir-se e tratar o outro, as tentativas de aproximação/afastamento, as ações e reações de ambos os personagens deixam claras e definidas as bordas bem delimitadas entre os dois mundos.

Para além de limites físicos ou geográficos, as fronteiras que se apresentam no filme $E l$ hombre de al lado são sociais e culturais. Invisível, mas nada sutil, a linha imaginária existente entre Leonardo e Victor implica em um olhar diferenciado e atento, capaz de perceber estas bordas e o seu papel na constituição dos próprios personagens e nos rumos que a história toma. É a alteridade - constantemente demarcada, sublinhada e cultivada que constrói identidades e modos de ser e estar no mundo, reforçando desigualdades e 
naturalizando a diferença. Nesse sentido, a película de Mariano Cohn e Gastón Duprat abre uma nova perspectiva para a discussão das fronteiras no campo fílmico como temática atemporal e fértil de significações.

\section{Referências}

AGIER, Michel. Antropologia da cidade: lugares, situações, movimentos. São Paulo: Terceiro Nome, 2011.

AUMONT, Jacques. L'Analyse des films. 2. ed. [S. l.]: Nathan, 1999.

AUMONT, Jacques; MARIE, Michel. Dicionário teórico e crítico de cinema. 2 ed. Campinas: Papirus, 2006.

BAUMAN, Zygmunt. Confiança e medo na cidade. Rio de Janeiro: Jorge Zahar, 2009.

GEERTZ, Clifford. A interpretação das culturas. Rio de Janeiro: LTC, 1989.

O HOMEM AO LADO. Direção de Mariano Cohn e Gastón Duprat. Produtor: Fernando Sokolowicz. Roteiro: Andrés Duprat. Argentina: Aleph Media, 2009.

PENAFRIA, Manuela. Análise de filmes: conceitos e metodologia(s). In: CONGRESSO SOPCOM, 6., 2009, Lisboa. Anais... Lisboa: Universidade Lusófona de Humanidades e Tecnologias, 2009. Disponível em: <http://bocc.unisinos.br/pag/bocc-penafria-analise.pdf>. Acesso em: 15 ago. 2013.

PESAVENTO, Sandra. Além das fronteiras. In: MARTINS, Maria Helena (Org.). Fronteiras culturais. São Paulo: Ateliê Editorial, 2002. p. 35-39.

VANOYE, Francis; GOLLIOT-LÉTÉ, A. Ensaio sobre a análise fílmica. Campinas: Papirus, 1994.

VIZER, Eduardo; CARVALHO, Helenice. Comunicação e socioanálises em comunidades e organizações sociais. Revista Latinoamericana de Ciencias de la Comunicación, São Paulo, v. 6, n. 11, p. 148-157, jul./dez. 2009.

\section{Cultural frontiers Cultural in the film EI hombre de al lado}

\footnotetext{
Abstract

From the observation of research on cultural frontiers, this article analyzes how these boundaries are constructed and represented in the Argentine movie El hombre de al lado (2009).
} 
The objective is to analyze and reflect on two sequences that represents boundary situations between the main characters: the first meeting and the party where one of them shows up without invitation. Actions, interactions and representations will be observed from the sight of a double relation: among the characters and with the social and spatial context.

\section{Keywords}

Cultural frontiers. Cinema. Communication.

\section{Fronteras culturales en la película El hombre de al lado}

\section{Resumen}

A partir de la observación de investigaciones sobre las fronteras culturales, este artículo analiza cómo se construyen y se representan estas fronteras en la película argentina El hombre de al lado (2009). El objetivo es analizar y reflexionar sobre dos secuencias que representan situaciones de frontera entre los personajes principales: el primer encuentro y la fiesta donde uno de ellos aparece sin ser invitado. Las acciones, interacciones y representaciones serán observadas desde una doble relación: de los personajes entre sí y con el contexto social y espacial.

\section{Palabras clave}

Fronteras culturales. Cine. Comunicación.

Recebido em 19/03/2014

Aceito em 02/12/2014 